\title{
Comparison of outpatient versus inpatient transurethral prostate resection for benign prostatic hyperplasia: Comparative, prospective bi-centre study
}

\author{
Jae Heon Kim, MD;* Jae Young Park, MD;* Ji Sung Shim, MD;* Jeong Gu Lee, MD;* Du Geon Moon, MD;* \\ Jeong woo Yoo, MD; Hoon Choi, MD; Jae Hyun Bae, MD*
}

*Department of Urology, Soonchunhyang University College of Medicine, Seoul, Korea; *Department of Urology, Korea University College of Medicine, Seoul, Korea

Cite as: Can Urol Assoc J 2014;8(1-2):e30-5. http://dx.doi.org/10.5489/cuaj.1370

Published online January 14, 2014.

\section{Abstract}

Introduction: We compare the symptomatic relief with urodynamic parameter change and operative safety of the outpatient transurethral resection in saline (TURIS-V) technique with inpatient transurethral resection of the prostate (TURP) for the management of benign prostatic hyperplasia (BPH).

Methods: This prospective cohort comparison study enrolled patients who needed BPH surgery. Between January 2010 and June 2011, outpatient TURIS-V was performed at 1 centre and the results of the treatment were compared with inpatient TURP performed at a separate hospital. Preoperative characteristics, including prostate volume, were similar in both groups. Perioperative data and any treatment complications were recorded. The analysis compared postoperative outcomes, including a 6-month postoperative International Prostate Symptom Score (IPSS), a quality of life (QoL) evaluation and a record of any changes in uroflowmetry findings, between the 2 groups.

Results: In the TURIS-V patient group, 75 patients agreed to be in the study. Of these, 69 ultimately complete the study. In the TURP group, 76 patients agreed and 71 of these completed the study. Both study groups were well-matched for age, IPSS, QoL and uroflowmetry findings. The TURIS-V group experienced both shorter operation times (54.6 vs. 74.8 minutes) and shorter catheterization times ( 2.2 vs. 4.2 days) when compared to the TURP group. There were comparable improvements in the 6-month postoperative IPSS, QoL, and uroflowmetry findings between the 2 groups. There were also equally low incidence rates of procedural complications.

Conclusions: Both TURIS-V and TURP relieve lower urinary tract symptoms in a similar way, with great efficacy and safety. Overall, TURIS-V had shorter operative and catheterization times compared to TURP. Notwithstanding the paper's limitations (non- randomized cohort comparison with possible selection or surgeon bias and small heterogeneous sample size), TURIS-V can be performed safely even in an outpatient setting.

\section{Introduction}

$\mathrm{BPH}$ is a chronic, complex disease that is commonly associated with inconvenient lower urinary tract symptoms. Although BPH is benign, it often negatively affects health and quality of life because it causes constant urinary obstruction and lower urinary tract irritation. ${ }^{1,2}$ Because of these complications, about $30 \%$ of elderly men opt for surgery. ${ }^{3}$

The outcome of BPH treatment should be efficient and lifelong improvement in symptoms. For several decades, the gold standard of BPH management was TURP or an open prostatectomy, which depended on prostate volume. Common side effects of both of these procedures included severe bleeding, retrograde ejaculation, stricture, incontinence, and electrolyte imbalances in the form of the transurethral resection (TUR) syndrome. ${ }^{4}$

These disadvantages have inspired the development of new surgical procedures that might replace TURP. Several new treatment modalities, such as laser vaporization (the fastest growing modality), have been developed to reduce TURP-related complications and to provide patients with the option of having these procedures performed in an outpatient setting. ${ }^{3}$

During the past few years, prostate resection using laser therapy has become increasingly popular because of its high efficacy and low morbidity. ${ }^{5}$ The recently developed TURISplasma vaporization (TURIS-V) laser technique is expected to relieve lower urinary tract symptoms (LUTS) caused by $\mathrm{BPH}$. This technique has shown comparable results and fewer complications in early- and short-term follow-up data compared to standard TURP. ${ }^{6}$ However, a comparison in the efficacy of the TURIS-V and TURP treatments has not yet been determined. We evaluate symptomatic relief with urodynamic parameter change, including safety profiles of TURIS-V, in outpatient or private office-based treatments compared with the conventional inpatient, hospital-based TURP operations in Korean patients. 


\section{Methods}

Between January 2010 and June 2011, a total of 156 patients were eligible. The inclusionary criteria were: (1) previous medical therapy failure; (2) severe LUTS with deleterious urodynamic parameters or recurrent, persistent urinary complications, such as hematuria; and (3) presence of a bladder stone. Exclusionary criteria were: (1) history of prostate-related surgery; (2) a prostate volume $>80 \mathrm{~mL}$; (3) neurogenic bladder; (4) urethral stricture; (5) coagulation disorders; (6) evidence of prostate cancer; (7) inadequate compliance; or (8) dementia. Patients were enrolled in the study voluntarily, and informed consent was obtained from all patients. The study was approved by ethical and research committees. Patients were treated at 2 centres (Korean University Ansan Hospital, Ansan, Korea; and the Tower Urology Clinic, Seoul, Korea), with each surgical method (TURIS-V and TURP) in 2 consecutive case series.

The procedures in this study were performed by 2 experienced urologists ( $\mathrm{Yu}$ and Bae). Bae performed 71 conventional TURP procedures using a 24-Fr Storz single-wire loop resectoscope (Karl Storz, Tuttlingen, Germany); mannitol solution irrigation was used for each case. The operations were performed under inpatient, hospital-based procedural control and required hospital admission. The TURIS-V operations were conducted by $\mathrm{Yu}$ with saline irrigation, using the Olympus SurgMaster UES-40 bipolar generator and a 24-Fr resectoscope. These operations were performed under outpatient, private, office-based procedural control. For these procedures, a round-shaped electrode was used to display a plasma corona on a cut surface and was steadily moved into direct contact with the enlarged prostate adenoma tissue, and produced almost bloodless vaporization. Patients were discharged with Foley catheters after the operation.

The basic enucleation of both procedures was similar. Each procedure began by making an incision at the proximal part of verumontanum from the 5 to the 7 o'clock positions. This was done to establish a cleavage plane at the apical region, which was identified by a smooth plane with clear vessels. The resectoscope tip was inserted into the cleavage plane, and the gland of the mid-lobe was dissected from the prostate capsule in a retrograde fashion toward the bladder neck using the loop and the tip of the resectoscope. The detachment area was extended both forward and bilaterally. In all of the procedures, $222-$ Fr Foley catheters were inserted and bladder irrigation was maintained for 6 to 12 hours after surgery. Perioperative data were recorded for both groups and included operating time, changes in hemoglobin, duration of catheterization, and any complications.

In the 6-month postoperative evaluation, the 2 groups had their prostate volumes rechecked, which was determined by transrectal ultrasound. Reduced tissue weight, percentage of reduced tissue weight (reduced tissue weight/preopera- tive prostate volume $\times 100$ ), operation efficiency (reduced tissue weight/operation time) were calculated. The patients were given initial assessments, which included International Prostate Symptom Scores (IPSS), the 8th question of IPSS (QoL), maximal urinary flow rates (Qmax) and post-voiding residual urine volume (PVR). Six months after the operations, follow-up assessments were obtained for each patient and included the IPSS, QoL, Qmax, and PVR. Additionally, changes in symptom scores and uroflowmetry findings, as well as any postoperative complications, were compared between the 2 groups. The Student's t-test was used for statistical analysis and a $p$ value $<0.05$ was set for statistical significance. All statistical analyses were performed by SPSS 12.0 (SPSS, Chicago, IL).

\section{Results}

From a total of 156 eligible patients, 5 did not consent to enter the trial and 2 were excluded from the TURP group due to incidental carcinomas (Fig. 1). A total of 151 patients completed the initial evaluation. During the follow-up period in the TURP group, 1 patient died and 2 patients were lost to follow-up. From the TURIS-V group, 6 patients were lost to follow-up. The number of dropouts was not significantly different between groups. The final statistical analysis included 69 patients in the TURIS-V group and 71 in the TURP group (Table 1). The mean (SD) age of the TURIS-V group was $65.2 \pm 8.5$ years and the mean age of the TURP group was $67.2 \pm 9.1$ years.

During the procedures, the operation time was shorter (54.6 vs. 74.8 minutes) for the TURIS-V group compared to the TURP group. In addition, the operation efficiency was higher $(0.47$ vs. 0.36$)$ for the TURIS-V group than for the TURP group. There were similar results for tissue reduction weights and percentages. There were also similar changes in hemoglobin a day after the operations. Catheterization time was significantly shorter for the TURIS-V group (4.2 days) than for the TURP group (2.2 days). There were no serious intraoperative complications, such as massive hemorrhage, which would require a transfusion or transurethral resection syndrome, and the rates of procedural complications were equally low between the 2 groups. There were 2 cases of delayed gross hematuria and 1 case of clot retention in the TURIS-V group. Similarly, there were 2 cases of delayed gross hematuria, 1 of clot retention and 1 of urethral stricture in the TURP group.

Patient symptoms and uroflowmetry findings were obtained in the follow-up analysis (Table 2). All patients completed 6 months of follow-up. Compared with the baseline data, there were significant improvements in IPSS, QoL, Qmax, and post-voiding residual urine outcomes after the surgeries for both the TURIS-V and TURP groups. Patients in both groups had statistically similar improvements. 
Kim et al.

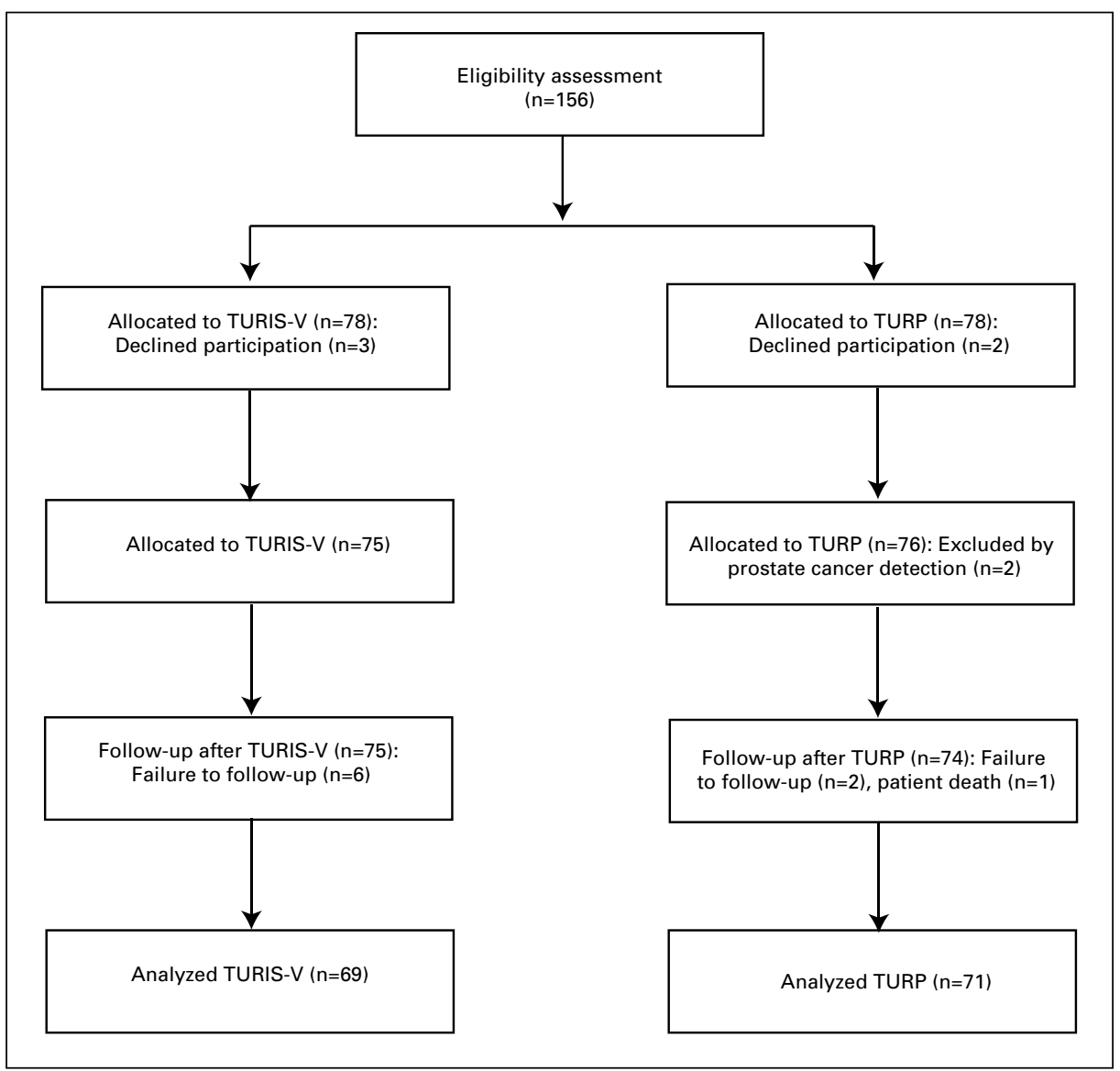

Fig. 1. Study flow diagram. TURIS-V: transurethral resection in saline; TURP: transurethral resection of the prostate.

\section{Discussion}

Although medical treatment can address most BPH cases, some BPH can progress and cause severe complications, such as acute urinary retention, and require BPH-related surgery.? Treatments have demonstrated that while pharmacotherapy is relatively safer than surgical treatment, surgery is more efficient for controlling LUTS. ${ }^{8}$ Until recently, TURP has been considered the gold standard for minimally invasive treatment for BPH when prostate volumes range from 30 to $80 \mathrm{~mL}{ }^{9}$

However, less invasive operative modalities have been developed to treat $\mathrm{BPH}$ to reduce TURP-related morbidity, and to maintain efficacy and minimize risk associated with BPH treatment. There are currently many alternatives, including microwave thermotherapy, radiofrequency ablation, bipolar resection or vaporization plus various laser based operations. In the United States, the proportions of $\mathrm{BPH}$-related surgery include monopolar TURP $(73 \%)$; photoselective vaporization of the prostate $(58 \%)$; TURIS-V (24\%); bipolar TURP (20\%); holmium laser ablation (18\%); thulium laser ablation ( $4 \%$ ) and laparoscopic or robotic prostatectomy ( $1 \%$ and $3 \%$, respectively). ${ }^{10}$ Complications from these various procedures mainly stem from serious distress of standard TURP, such as transfusion rate, transurethral resection syndrome and even patient death from the operation. ${ }^{11}$

In Korea, PVP vaporization, which uses photoselective laser therapy, has been used to treat $\mathrm{BPH}$ as frequently as TURP since 2006. ${ }^{12}$ An analysis of these 2 methods indicated that the use of the Greenlight laser, which achieved an optimal coagulation depth of up to $3 \mathrm{~mm}$ in the prostate tissue, allowed for earlier mobilization, less blood loss and lower transfusion rates in the PVP group compared to the TURP group. ${ }^{13,14}$

The goals of both TURP and PVP are to create visible cavities, and it has been reported that TURP results in a better size reduction in prostate volume when compared with PVP. Furthermore, the rate of re-intervention is relatively high with PVP because it affects the retention of coagulated, necrotic tissue after vaporization. ${ }^{15,16}$ These results demonstrate that while there have been significant improvements in terms of speed and efficiency of tissue vaporization over time, even with the development of Greenlight technology, further improvements are required especially for outpatient, private, office-based operations. 


\begin{tabular}{|c|c|c|c|}
\hline Parameters & $\begin{array}{c}\text { TURIS-V } \\
(\mathrm{n}=69)\end{array}$ & $\begin{array}{l}\text { TURP } \\
\text { (n=71) }\end{array}$ & $p$ value \\
\hline \multicolumn{4}{|c|}{ Baseline parameter } \\
\hline Age (years) & $65.2 \pm 8.5$ & $67.2 \pm 9.1$ & 0.19 \\
\hline Initial IPSS score & $21.4 \pm 8.5$ & $21.1 \pm 8.9$ & 0.26 \\
\hline Initial QoL score & $4.3 \pm 1.4$ & $4.1 \pm 1.3$ & 0.33 \\
\hline TPV (g) & $49.6 \pm 11.7$ & $51.4 \pm 17.8$ & 0.12 \\
\hline Omax (mL/sec) & $7.4 \pm 2.3$ & $6.9 \pm 3.1$ & 0.11 \\
\hline PVR (mL) & $169.2 \pm 14.0$ & $180.1 \pm 14.4$ & 0.55 \\
\hline \multicolumn{4}{|c|}{ Operative parameter } \\
\hline Operating time (min) & $54.6 \pm 13.8$ & $74.8 \pm 14.2^{*}$ & $<0.01$ \\
\hline Reduced tissue weight (g) & $25.7 \pm 6.0$ & $27.3 \pm 8.9$ & 0.21 \\
\hline $\begin{array}{l}\text { Percentage of reduced tissue } \\
(\%)\end{array}$ & $51.8 \pm 17.2$ & $53.1 \pm 22.1$ & 0.20 \\
\hline Operation efficiency ( $\mathrm{g} / \mathrm{min}$ ) & $0.47 \pm 0.2^{*}$ & $0.36 \pm 0.1$ & 0.01 \\
\hline Hemoglobin decrease (g/dL) & $1.0 \pm 0.3$ & $1.1 \pm 0.2$ & 0.29 \\
\hline Catheterization time (days) & $2.2 \pm 0.8$ & $4.2 \pm 0.8^{*}$ & $<0.01$ \\
\hline Complication rate (\%) & $3(4.3 \%)$ & $4(5.6 \%)$ & 0.45 \\
\hline
\end{tabular}

TURIS-V: transurethral resection in saline; TURP: transurethral resection of the prostate; IPSS: International Prostate Symptom Score; QoL: quality of life; TPV: total prostate volume; PVR: post-void residual.

One new alternative treatment that has emerged, which safely provides equivalent improvement of the LUTS parameters, is holmium laser transurethral enucleation of the prostate (HoLEP). Overall advantages of HoLEP include up to an $80 \%$ reduction of PSA after operation, and from these results, it was concluded that HoLEP could be used for the entire resection of the adenoma. ${ }^{17}$ Moreover, HoLEP has been demonstrated to be an effective treatment method for various $\mathrm{BPH}$ sizes and in concurrence with adenoma, a minimal bleeding disorder and electrolyte imbalance. Results indicated that HoLEP significantly improved the IPSS, Qmax, and PVR outcomes when compared with TURP and the rate of procedural complications was similar between the 2 methods. ${ }^{18,19}$ However, retrograde laser fibre dissection may be very complex for urologists who are more familiar with antegrade resection methods applied with TURP. It was reported that inexperienced urologic surgeons were in need of at least 50 cases to achieve familiarity with the HoLEP procedure; adjusting for this learning curve may be difficult. ${ }^{20}$

In addition, the holmium laser instruments are relatively expensive and HoLEP requires an unfamiliar, dangerous mechanical tissue morcellator for proper application. This may be why HoLEP has not been popular with private clinics and even with some inpatient hospital-based clinics.

Recently, the use of bipolar electrosurgical technology, TURIS-V, has demonstrated lower complication rates and comparable results to the standard TURP. Plasma corona on the surface of the spherical-shaped electrode by highfrequency electrosurgical generator connects with the tissue surface and performs smooth vapor-resection with least tissue irregularities or fragments and no additional thermal injury to the adjacent tissue. In addition, TURIS-V allows hemostasis during tissue resection. Therefore, TURIS- $V$ is advantageous because it causes relatively few changes in tissue characteristics and minimal bleeding. During this procedure, the operator is able to identify the adenoma tissue and the muscles with better accuracy. ${ }^{21}$ As a result, TURIS-V provides an excellent operative duration (35.1 vs. 50.4 minutes), and a shorter catheterization period (23.8 vs. 71.2 hours) and hospital stay (47.6 vs. 93.1 hours) compared with TURP in a prospective, randomized trial. Additionally, there were greater symptom improvements with the TURIS-V group of patients. ${ }^{6}$

In recent retrospective data, TURIS- $V$ was characterized by a shorter operation time (58.7 minutes) than the TURP group (73.9 minutes), even though the results were not statistically significant. The study also indicated that TURIS-V significantly decreased the catheterization period (2.8 vs. 4.3 days) and hospital stay ( 4.9 vs. 6.7 days) compared with conventional TURP. Both groups had similar improvements in subjective and objective voiding parameters and these results were sustained throughout the 6 months of followup. ${ }^{12}$ There were no observable differences in the complication profiles. ${ }^{6,12}$

In this study, the results indicated that the operation and the catheterization time were shorter for the TURIS-V group than for the TURP group. To measure these results, we used operation efficiency (reduced tissue weight/operation time) and percentage reduced tissue (reduced tissue weight/preoperative prostate volume $\times 100$ ). Operation efficiency is an indirect indicator of tissue resectability within a limited amount of time. Therefore, high operation efficiency with TURIS-V (0.47) when compared with TURP $(0.36)$ suggests

\begin{tabular}{|c|c|c|c|c|c|c|c|}
\hline \multirow{2}{*}{ Parameters } & \multicolumn{3}{|c|}{ TURIS-V (n=69) } & \multicolumn{3}{|c|}{ TURP (n=71) } & \multirow{2}{*}{$\begin{array}{c}\text { Between groups } \\
p \text { value }\end{array}$} \\
\hline & Baseline & Follow-up & Difference (\%) & Baseline & Follow-up & Difference (\%) & \\
\hline IPSS score & 21.4 & 8.6 & $12.8(59.8)$ & 21.1 & 7.8 & $13.3(63.0)$ & 0.77 \\
\hline QoL score & 4.3 & 2.1 & $2.2(51.2)$ & 4.1 & 2.1 & $2.0(48.8)$ & 0.63 \\
\hline Omax (mL/sec) & 7.4 & 19.3 & $11.9(160.8)$ & 6.9 & 19.2 & $12.3(178.2)$ & 0.86 \\
\hline PVR (mL) & 169.2 & 49.1 & $120.1(70.9)$ & 180.1 & 50.5 & $129.6(72.0)$ & 0.90 \\
\hline
\end{tabular}

TURIS-V: transurethral resection in saline; TURP: transurethral resection of the prostate; IPSS: International Prostate Symptom Score; QoL: quality of life; TPV: total prostate volume; PVR: post-void residual. 
Kim et al.

that TURIS-V can remove prostate tissue more quickly. This is important for outpatient clinics because longer operative times could be related to higher morbidity. It is also important because clinicians can save time during the operation because less time is needed to remove the same amount of tissue.

In regards to the rate of tissue extraction, there was no observable difference in the percentage of reduced tissue between the 2 groups. Studies have indicated that greater amounts of tissue extraction could lead to better symptomatic relief and lower incidences of re-operation. ${ }^{16}$ Patients from the 2 studies had comparable symptomatic improvements during follow-up, which may indirectly reflect the proportion of tissue extraction. The complication rates were equally low with each procedure in this study, as well as in previous studies. ${ }^{6,12}$

The initial short-term results of TURIS-V seem promising, and we sought to gain a different view of TURIS-V. Because the insurance charges for TURIS-V, PVP, and TURP are basically equal in Korea, TURIS- $V$ may be more costeffective than PVP because of the lower prices of the system equipment. TURIS-V may also be more effective because the overall efficacy of TURP and TURIS-V is better than PVP laser treatment, even though there is no discrepancy in the rates of procedural complications. However, HoLEP treatment requires a longer learning period and the equipment costs more, even for hospital-based clinicians. Even with the advances in TURP, it continues to be an inaccessible procedure in private clinics because of the relatively high morbidity and subsequent need for hospital admission. From these results, it is recommended that outpatient practices adopt TURIS-V as treatment demands for BPH increase. The results indicate that operation efficiency and tissue extraction rates are more advantageous with TURIS-V and adaptation of this procedure will save time and be clinically beneficial.

TURIS-V is an important endoscopic treatment alternative for BPH. Studies have demonstrated that TURIS-V has superior efficacy, as well as comparable short-term results and complication rates when compared with TURP; TURIS-V is quickly gaining more popularity in Korea. In our opinion, TURIS-V is a highly optimized method for outpatient operations. In addition, because of these beneficial aspects, TURIS-V is also a promising inpatient method and could be applied to daily care operations.

Some of the limitations of this study were that the groups were not heterogeneous in nature, and were not randomly assigned to groups. Patient selection, surgeon bias or expertise may have significantly contributed to the better operative time and efficiency in the TURIS-V group. The sample size was also relatively small. Though Yu and Bae are experienced urologists with similar age and case sample size, skill differences in physicians is one a big limitation. Nevertheless, the study demonstrated the effectiveness and safety of TURIS-V as an outpatient operation in comparison with TURP. Although there may be methodological problems, the clinical efficiency of TURIS- $V$ can be observed by many urology clinicians in Korea. We need long-term, well-designed studies to establish the long-term advantages and viability of this promising procedure in both outpatient and inpatient urology clinics.

\section{Conclusion}

TURIS-V and TURP are both safe and minimally invasive techniques with high efficacy for patients with BPH. TURIS-V results were comparable with the TURP results. In addition, TURIS-V can be efficiently performed as an outpatient procedure, especially in operation and catheterization time. It is reasonable to expect that TURIS-V could become a valuable endoscopic treatment alternative for $\mathrm{BPH}$.

Competing interests: Dr. Choi and Dr. Bae declare no competing financial or personal interests.

This paper has been peer-reviewed.

\section{References}

1. Wang JY, Liu M, Zhang YG, et al. Relationship between lower urinary tract symptoms and objective measures of benign prostatic hyperplasia: A Chinese survey. Chin Med J 2008;121:2042-5.

2. Parsons JK. Benign prostatic hyperplasia and male lower urinary tract symptoms: Epidemiology and risk factors. Curr Bladder Dysfunct Rep 2010;5:212-8. hittp://dx.doi.org/10.1007/s11884-010-0067-2

3. Malseb BS, Yu X, McBean AM, et al. National trends in surgical therapy for benign prostatic hyperplasio in the United States (2000-2008). Urology 2012;79:1111-6. http://dx.doi.org/10.1016/i.urology.2011.11.084

4. Madersbacher $S$, Marberger $M$. Is transurethral resection of the prostate still justified? BJU Int 1999;83:227-37. http://dx.doi.org/10.1046/j.1464-410x.1999.00908.x

5. Marks AJ, Teichman JM. Lasers in clinical urology: state of the art and new horizons. World I Urol 2007;25:227-33. http://dx.doi.org/10.1007/s00345-007-0163-x

6. Geavlete B, Multescu R, Dragutescu M, et al. Transurethral resection (TUR) in saline plasma vaporization of the prostate vs standard TUR of the prostate: 'The better choice' in benign prostatic hyperplasia? BJU Int 2010;106:1695-9. http://dx.doi.org/10.1111/i.1464-410X.2010.09433.x

7. McConnell JD, Bruskewitz R, Walsh $\mathrm{P}$, et al. The effect of finasteride on the risk of acute urinary retention and the need for surgical treatment among men with benign prostatic hyperplasia. Finasteride LongTerm Efficacy and Safety Study Group. N Engl J Med 1998;338:557-63. http://dx.doi.org/10.1056/ NEJM199802263380901

8. Masumori N, Kamoto T, Seki N, et al.; Committee for Clinical Guideline for Benign Prostatic Hyperplasia. Surgical procedures for benign prostatic hyperplasia: Anationwide survey in Japan. Int J Urol 2011;18:16670. http://dx.doi.org/10.1111/i.1442-2042.2010.02687.x

9. Homma Y, Gotoh M, Yokoyama 0 , et al. Outline of JUA clinical guidelines for benign prostatic hyperplasia. Int J Urol 2011;18:741-56. http://dx.doi.org/10.1111/i.1442-2042.2011.02860.x

10. Nora L, Hui X, Lori L. Trends in surgical management for benign prostatic hyperplasia. J Urol (Suppl) 2011;185:e838. http://dx.doi.org/10.1016/i.juro.2011.02.2294

11. Mebust WK, Holtgrewe HL, Cockett AT, et al. Transurethral prostatectomy: Immediate and postoperative complications. A comparative study of 13 participating institutions evaluating 3885 patients. J Urol 2002;167:5-9. http://dx.doi.org/10.1016/S0022-5347(05)65370-0

12. Lee YT, Ryu YW, Lee DM, et al. Comparative Analysis of the Efficacy and Safety of Conventional Transurethral Resection of the Prostate, Transurethral Resection of the Prostate in Saline (TURIS), and TURIS-Plasma Vaporization for the Treatment of Benign Prostatic Hyperplasia: APilot Study. Korean J Urol 2011;52:763-8. http://dx.doi.org/10.4111/kju.2011.52.11.763 
13. Lee R, Gonzalez RR, Te AE. The evolution of photoselective vaporization prostatectomy (PVP): Advancing the surgical treatment of benign prostatic hyperplasia. World I Urol 2006;24:405-9. http://dx.doi. org/10.1007/s00345-006-0094-y

14. Malek RS, Kang HW, Coad JE, et al. Greenlight photoselective 120-watt 532-nm lithium triborate laser vaporization prostatectomy in living canines. J Endourol 2009;23:837-45. http://dx.doi.org/10.1089/ end.2008.0669

15. Bachmann A, Schurch L, Ruszat R, et al. Photoselective vaporization (PVP) versus transurethral resection of the prostate (TURP): A prospective bi-centre study of perioperative morbidity and early functional outcome. Eur Urol 2005;48:965-72. http://dx.doi.org/10.1016/i.eururo.2005.07.001

16. Horasanli K, Silay MS, Altay B, et al. Photoselective potassium titanyl phosphate (KTP) laser vaporization versus transurethral resection of the prostate for prostates larger than $70 \mathrm{~mL}$ : A short-term prospective. Urology 2008;71:247-51. http://dx.doi.org/10.1016/i.urology.2007.09.017

17. Krambeck AE, Handa SE, Lingeman JE. Holmium laser enucleation of the prostate for prostates larger than 175 grams. J Endourol 2010;24:433-7. http://dx.doi.org/10.1089/end.2009.0147

18. Ahyai SA, Lehrich K, Kuntz RM. Holmium laser enucleation versus transurethral resection of the prostate: 3-year follow-up results of a randomized clinical trial. Eur Urol 2007;52:1456-63. http://dx.doi. org/10.1016/i.eururo.2007.04.053
19. Kuntz RM, Lehrich K, Ahyai SA. Holmium laser enucleation of the prostate versus open prostatectomy for prostates greater than 100 grams: 5-year follow-up results of a randomized clinical trial. Eur Urol 2008;53:160-6. http://dx.doi.org/10.1016/i.eururo.2007.08.036

20. Shah HN, Mahajan AP, Sodha HS, et al. Prospective evaluation of the learning curve for holmium laser enucleation of the prostate. J Urol 2007;177:1468. http://dx.doi.org/10.1016/i.juro.2006.11.091

21. Zhang SY, Hu H, Zhang XP, et al. Efficacy and safety of bipolar plasma vaporization of the prostate with "button-type" electrode compared with transurethral resection of prostate for benign prostatic hyperplasia. Chin Med J (Engl) 2012;125:3811-4.

Correspondence: Dr. Jae Hyun Bae, Department of Urology, Korea University Ansan Hospital, Korea University College of Medicine, 123 Jeokgeum-ro, Danwon-gu, Ansan 425-707, Korea; fax: +82-31-412-5194; urobae@genetherapy.or.kr 